BORDINI, Ricardo. 2018. Expanded Atonal Voice-Leading Space for Trichords: an auxiliary model for generating pre-compositional material. MUSICA THEORICA. Salvador: TeMA, 201805, p. 108-127.

\title{
Expanded Atonal Voice-Leading Space for Trichords: an auxiliary model for generating pre-compositional material
}

\author{
Espaço Atonal Expandido de Encadeamentos para Tricordes: \\ um modelo auxiliar para a geração de material pré-composicional
}

\author{
Ricardo Mazzini Bordini \\ Universidade Federal do Maranhão \\ mazbord@gmail.com
}

\begin{abstract}
This paper discusses an atonal voice-leading space for trichords as stated by Straus (2005) after Morris (1998), expanded by insertion of a new operation. Examined in detail are the operations and rules for chaining set classes by semitones inside that space; provisions for further approaches including a new method for chaining; suggestions on some pathways to traverse it thoroughly, and a quick reference guide for voice-leading sub-spaces.
\end{abstract}

Keywords: Post-Tonal Theory, Atonal Voice-Leading Space, Voice-Leading Space Models.

Resumo: Este documento estuda um espaço atonal de encadeamentos para tricordes conforme apresentado por Straus (2005) seguindo Morris (1998), expandido pela inserção de uma nova operação. São examinados em detalhe: as operações e regras para concatenar as classes de conjuntos por semitons naquele espaço; provisões para outras abordagens, incluindo um novo método de encadeamento; sugestões de alguns percursos para cruzá-lo completamente e um guia de referência para subespaços de encadeamentos.

Palavras-chave: teoria pós-tonal; espaço atonal de encadeamentos; modelos de espaço de encadeamentos. 
BORDINI, Ricardo. 2018. Expanded Atonal Voice-Leading Space for Trichords: an auxiliary model for generating pre-compositional material. MUSICA THEORICA. Salvador: TeMA, 201805, p. 108-127.

\section{1 - Introduction}

This article $^{1}$ focuses on an expanded atonal voice-leading space for trichords. Voice-leading space concept provides a useful tool for understanding how set classes function and relate one to another. After close examination of all operations involved, rules for chaining set classes by semitone inside that space are stated, and a new method for chaining is achieved. This processes leads to the concept of sub-spaces and to the idea of pathways or routes to traverse thoroughly such an expanded atonal voice-leading space.

According to Straus (2005, 110-112), after Morris (1998), set classes offset by a distance of only one voice-leading semitone constitute a "voice-leading space". Adding or subtracting one semitone to each member of a set produces four different results: 1) one set is mapped into another and their prime forms differ by one semitone. For example: $\operatorname{sc}(012)$ and $\operatorname{sc}(013)$ have this property; 2) the operation maps a set into another set and their prime forms differ by two semitones. In this case, two members of their prime forms are displaced by one semitone each. Considering the very same example Straus uses to explain the process of mapping the atonal voice-leading space for trichords, $\mathrm{sc}(013)$ is related to $\mathrm{sc}(024)$ by a voice-leading semitone and their prime forms exhibit two members displaced by one semitone each; 3) a set is mapped into another set and they both are members of the same set class, and 4) a set is mapped into a multiset (sets in which members are allowed to be repeated). Beyond that, this paper will consider another relationship in which, for instance, $\mathrm{sc}(015)$ is also related with $\mathrm{sc}(024)$. As with prime forms described in item 2 above, two members of their prime forms are also displaced by a semitone. The difference rests on the fact that one member has increased by a semitone while the other has decreased by a semitone. Nonetheless, this relationship is not shown in the regular voice-leading space map for trichords, therefore, those set classes are not considered as related by a voice-leading semitone. Two other pairs of set classes: $\operatorname{sc}(016)$ with $\operatorname{sc}(025)$, and $\operatorname{sc}(027)$ with $\mathrm{sc}(036)$ also have the same relationship.

An expanded atonal voice-leading space as proposed here will have the following features: 1) it will use exclusively set classes prime forms, meaning it

\footnotetext{
${ }^{1}$ This paper is part of a Post-Doctoral Project sponsored by the Brazilian Government Agency Comissão de Aperfeiçoamento de Pessoal de Nível Superior (CAPES), which was developed at the University of California at Santa Cruz (UCSC) in collaboration with Dr. David Evan Jones from July, 2010 until June, 2011. I would like to acknowledge Dr. Joseph N. Straus for giving permission to use and alter his atonal voice-leading space representation and for his many valuable suggestions and corrections. My deepest thanks to Dr. Josef Sekon and Maria Davico for having revised and corrected this text. Special thanks to Matthew Mitchell for his many insightful comments. It was first presented at the III Encontro da Associação Brasileira de Teoria e Análise Musical held in João Pessoa (PB) on November 5, 2018.
} 
will be a complete OPTIC system (see Callender 2008, and Tymoczko 2011); 2) it will not admit multisets, and 3) it will consider other operations besides those commonly used (for a more complex discussion on operations see Cook 2005). Regarding this last aspect, formulating regular operations as +1 OR -1 , one will find proposed new operations formulated as +1 AND -1 . Tymoczko's models will not be consider, because multisets actually change the real interval-class content (cardinality) of sets, and Cohn's tridimensional models are difficult to manage for the purpose of practical musical usage, often requiring animations or other multimedia tools. Although it is very simple to make up a voice-leading space for trichords, the same is not true regarding tetrachords, pentachords and hexachords, which will require more complex representational models as proposed by Cohn (2003), Callender (2008), and Tymoczko (2011). However, the present work will adhere to a more practical, simpler voice-leading space representation.

The map of relationships presented by Straus is useful in musical analysis and also as a compositional tool for guiding the composer or analyst through a chain of possible "modulations." His representation of voice-leading space is the starting point for the one proposed in this article because it provides a simpler yet complete map. The expanded voice-leading map proposed here will include the original and some new relationships that have not yet been contemplated. A map showing different connection types being used to link set classes would bring to light additional interesting relationships as will be seen later. A closer look at the rules governing the buildup of the voice-leading space will help clarify it.

\section{2 - Method}

Setting up a method for a voice-leading space starts by deducing the recursive process in which one semitone is added to each member of a set class as shown in Figure 1. Any two sets with one member offset by only one semitone can then be connected. One can see that set classes are arranged by columns and also how each column can be thought of as a layer. The level of each layer is determined by the second member of each set class (all set classes start with 0 , second member is 1 in the first column, 2 in the second column, and so on). 
BORDINI, Ricardo. 2018. Expanded Atonal Voice-Leading Space for Trichords: an auxiliary model for generating pre-compositional material. MUSICA THEORICA. Salvador: TeMA, 201805, p. 108-127.

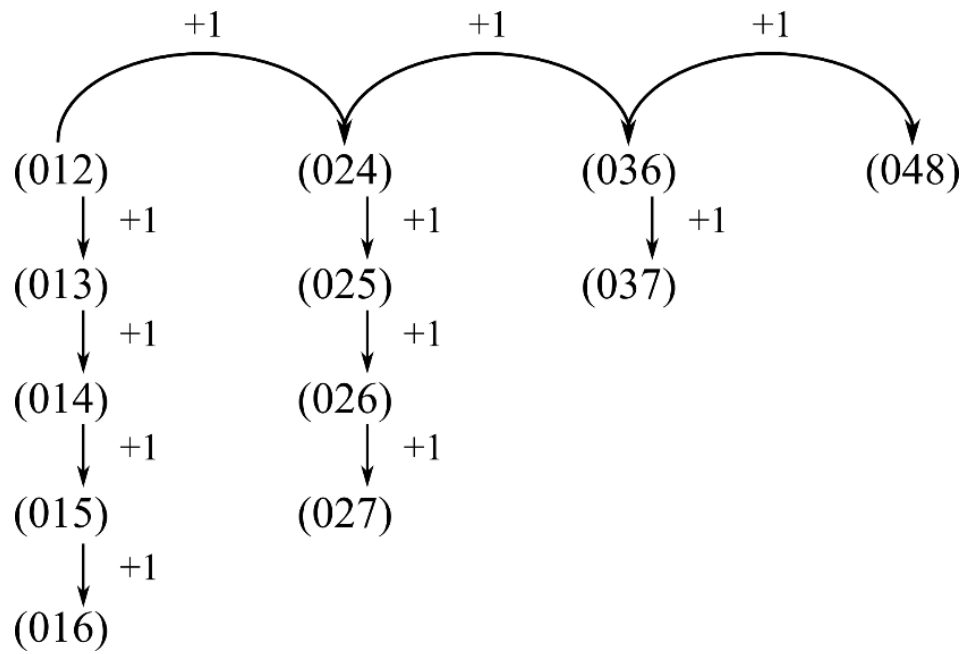

Figure 1: Layered disposition of trichords

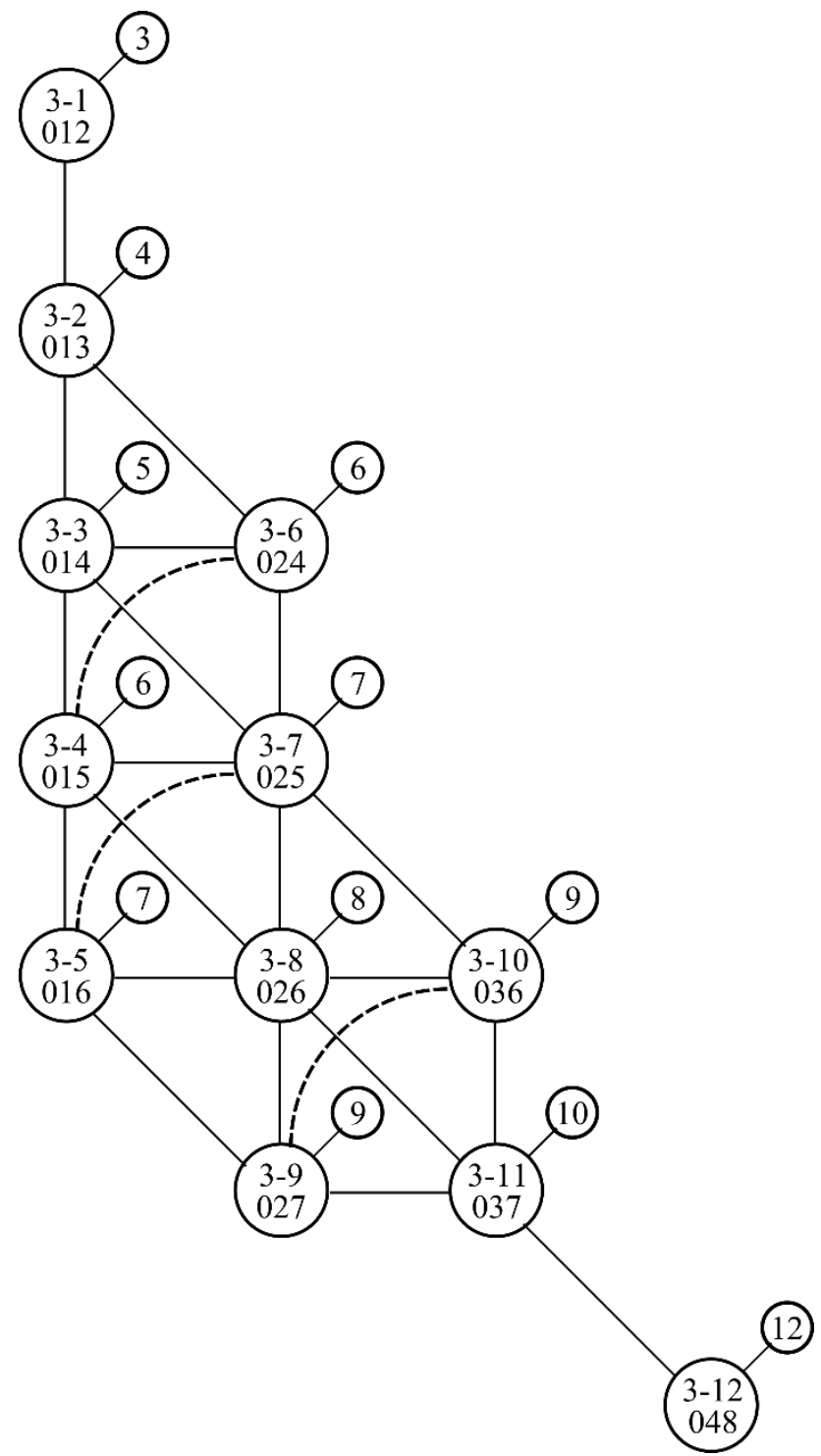

Figure 2: An atonal voice-leading space map for trichords with added sum-classes 
BORDINI, Ricardo. 2018. Expanded Atonal Voice-Leading Space for Trichords: an auxiliary model for generating pre-compositional material. MUSICA THEORICA. Salvador: TeMA, 201805, p. 108-127.

Once all sets have been obtained, the rules to connect any two set classes that can be related by voice-leading space are applied. Usually this is done by adding or subtracting one semitone to each member of a set at a time and converting the results into prime form if they already were not. We have been calling these operations "original" operations. These and other operations will be discussed in more detail later. By now, one is assumed to consider a special connection regarding those three pairs of set classes mentioned in the second paragraph. Those set classes are connected by dashed curved lines in Figure 2 above derived from the one proposed by Straus (2005, p. 111).

The process just discussed can be accomplished intuitively; however, one can find an easier, quicker, and more reliable method for chaining set classes within the voice-leading space for trichords. Referring once again to Figure 2, one notices an additional feature of this new map. A small circle attached to each set class contains the sum of all members inside that particular set class (for a different and more in-depth approach to sum-classes see Cohn 1998). Assigning to those sum-classes the letter $\mathbf{S}$, one sees in closer detail how those sums operate using the previous process. Assigning $S_{1}$ to the sum-class for a set class and $S_{2}$ to any other, those set classes are connected in the voice-leading space when:

$$
\text { (a) } \mathrm{S}_{1} \pm 1=\mathrm{S}_{2} \quad \text { or } \quad \mathrm{S}_{1} \pm 2=\mathrm{S}_{2}
$$

It is easy to understand and confirm, because all trichords start with 0 and the remaining two members may be increased or decreased by a semitone. When comparing two set classes there are only two possibilities: 1) if just one member has increased or decreased by semitone the sum-class will differ by plus or minus $1 ; 2$ ) If two members have increased or decreased by one semitone each the sumclass will differ by plus or minus 2 . While the first equation is always true, there is a condition that must be satisfied regarding the second one in order for it to be valid. Involved set classes cannot pertain to the same layer. Inside the same layer there are some sets offset by 2 in the sum-class which must not be connected because they do not result from a single voice-leading semitone operation. This happens when just one member is offset by two voice-leading semitones. A distinction between layers must be made in order to validate the second rule. The simplest way to distinguish layers is to classify them according to the second member which can be 1,2,3 or 4 . Assigning $\mathrm{L}_{1}$ to a set class in any layer and $\mathrm{L}_{2}$ to another one and providing they are located in adjacent layers, one deducts the following:

(b) $\mathrm{S}_{1} \pm 1=\mathrm{S}_{2} \quad$ or $\quad \mathrm{S}_{1} \pm 2=\mathrm{S}_{2} \quad$ and $\quad \mathrm{L}_{1} \pm 1=\mathrm{L}_{2}$

A further advantage of assuming a layered distribution of set classes among the voice-leading space is that sets with the same layer membership are 
BORDINI, Ricardo. 2018. Expanded Atonal Voice-Leading Space for Trichords: an auxiliary model for generating pre-compositional material. MUSICA THEORICA. Salvador: TeMA, 201805, p. 108-127.

easier to group. They also have a more similar sounding feature. All sets in any particular layer start with the same interval between the first and second member and continue ascending chromatically through the second and third members. In addition, each first set of the four layers shows increments ranging from a minor second to a major third between the first and second members.

For any two set classes, if its sum-class difference is greater than 2 or lesser than -2 , they are not connected in the voice-leading space. Finally, those sets previously not connected in the voice-leading space (those in which one member has been increased and some other has been decreased) must now be included. When the sum-class of two set classes is equal $\left(S_{1}=S_{2}\right)$, it fulfills the missing condition and our method is completed:

(c) $\mathrm{S}_{1} \pm 1=\mathrm{S}_{2} \quad$ or $\quad \mathrm{S}_{1} \pm 2=\mathrm{S}_{2}\left(\mathrm{~L}_{1} \pm 1=\mathrm{L}_{2}\right) \quad$ or $\quad \mathrm{S}_{1}=\mathrm{S}_{2}$

The main purpose of this method is to supply an easy way to figure out if two sets are connected in the voice-leading space. A more detailed representation for voice-leading space for trichords follows. Figure 3 is almost identical to the previous one except that now it has been rotated 90 degrees to the left and different connectors have been added. Those connectors assist to figure where one can move and also the quality of the movement inside the voice-leading space. Concerning connectors keep in mind that the first member is always zero and never changes, and that prime forms are dealt with here. Solid line connectors indicate one is moving forward or backward within the same layer i.e., the second member is fixed and the third member is increased or decreased by one semitone. Dotted connectors indicate one is moving upward or downward between layers i.e., the second member is increased or decreased by one semitone and the third member is fixed. Diagonal dash-dotted connectors show one is moving between layers and simultaneously moving forward or backward i.e., both the second and the third members are increased or decreased by a semitone - sum-classes differ by 2 . Finally, curved dashed connectors imply one is also moving between layers but with the already mentioned special feature: one member is increased and the other is decreased by one semitone. These different qualities of movement within the voice-leading space yield the concept of traversing it partially or entirely through pathways as will be discussed later. 
BORDINI, Ricardo. 2018. Expanded Atonal Voice-Leading Space for Trichords: an auxiliary model for generating pre-compositional material. MUSICA THEORICA. Salvador: TeMA, 201805, p. 108-127.

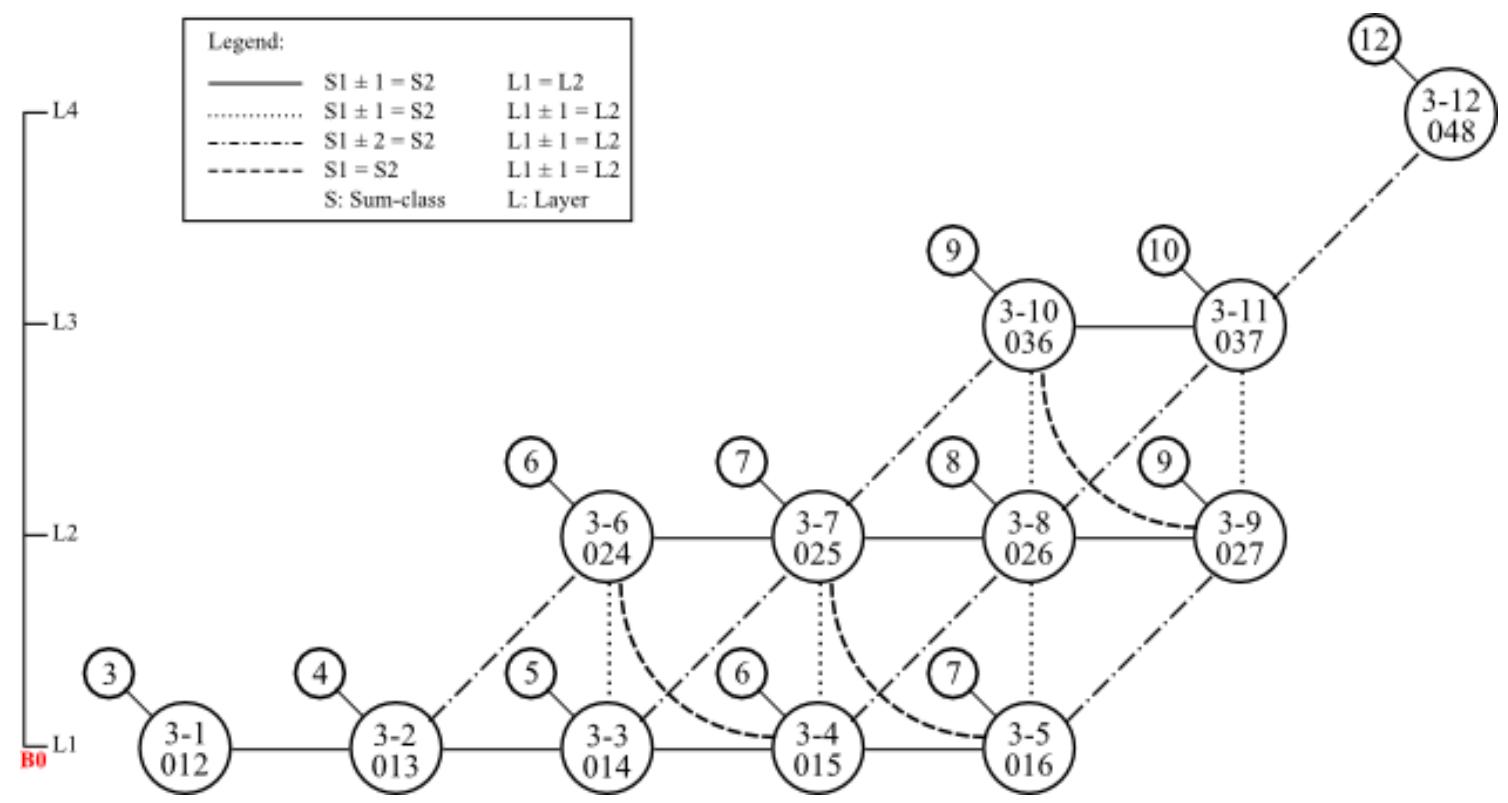

Figure 3: An expanded atonal voice-leading space map for trichords

\section{3 - Operations}

A thorough study of all voice-leading space operations available follows. The most basic operation requires the addition or subtraction of just one semitone to each member of a set class at a time. Available possibilities are shown on Table 1 and their corresponding connections are depicted in Figure 4. Conventions used in Table 1 and Figure 1 are: M1+ means one semitone was added to the first member of a set class, M1- means one semitone was subtracted from the first member of a set class, and so on. Cells containing multisets are shadowed in pale brown and cells containing operations that map a set class into its own set class are shadowed in pale green. As one can see in Figure 4, in some cases, there is more than one option to connect the same pair of set classes. For instance, to move from $\mathrm{sc}(024)$ to $\mathrm{sc}(014)$ one can either operate M2+ or M2-.

\begin{tabular}{|l|l|l|l|l|l|l|}
\hline & \multicolumn{1}{|c|}{ M1+ } & \multicolumn{1}{c|}{ M1- } & \multicolumn{1}{c|}{ M2+ } & \multicolumn{1}{c|}{ M2- } & \multicolumn{1}{c|}{ M3+ } & \multicolumn{1}{c|}{ M3- } \\
\hline$(012)$ & $(112)$ & (B12) $=(013)$ & $(022)$ & $(002)$ & $(013)$ & $(011)$ \\
\hline$(013)$ & $(113)$ & $($ B13 $)=(024)$ & $(023)=(013)$ & $(003)$ & $(014)$ & $(012)$ \\
\hline$(014)$ & $(114)$ & $($ B14 $)=(025)$ & $(024)$ & $(004)$ & $(015)$ & $(013)$ \\
\hline$(015)$ & $(115)$ & $(\mathrm{B} 15)=(026)$ & $(025)$ & $(005)$ & $(016)$ & $(014)$ \\
\hline$(016)$ & $(116)$ & $(\mathrm{B} 16)=(027)$ & $(026)$ & $(006)$ & $(017)=(016)$ & $(015)$ \\
\hline$(024)$ & $(124)=(013)$ & $(\mathrm{B} 24)=(025)$ & $(034)=(014)$ & $(014)$ & $(025)$ & $(023)=(013)$ \\
\hline$(025)$ & $(125)=(014)$ & $(\mathrm{B} 25)=(036)$ & $(035)=(025)$ & $(015)$ & $(026)$ & $(024)$ \\
\hline$(026)$ & $(126)=(015)$ & $(\mathrm{B} 26)=(037)$ & $(036)$ & $(016)$ & $(027)$ & $(025)$ \\
\hline$(027)$ & $(127)=(016)$ & $(\mathrm{B} 27)=(037)$ & $(037)$ & $(017)=(016)$ & $(028)=(026)$ & $(026)$ \\
\hline$(036)$ & $(136)=(025)$ & $(\mathrm{B} 36)=(037)$ & $(046)=(026)$ & $(026)$ & $(037)$ & $(035)=(025)$ \\
\hline$(037)$ & $(137)=(026)$ & $(\mathrm{B} 37)=(048)$ & $(047)=(037)$ & $(027)$ & $(038)=(037)$ & $(036)$ \\
\hline$(048)$ & $(148)=(037)$ & $(\mathrm{B} 48)=(037)$ & $(058)=(037)$ & $(038)=(037)$ & $(049)=(037)$ & $(047)=(037)$ \\
\hline
\end{tabular}

Table 1: Results obtained by operating members one by one 
BORDINI, Ricardo. 2018. Expanded Atonal Voice-Leading Space for Trichords: an auxiliary model for generating pre-compositional material. MUSICA THEORICA. Salvador: TeMA, 201805, p. 108-127.

Examination of Figure 4 confirms the four possible results discussed in the second paragraph. Adding or subtracting one semitone to the third member displaces the set rightward or leftward respectively to the next available set class on the same layer (horizontal movement). If there is no set class to the right, it will be mapped into its own set class when it is on the first or third layers. It will be mapped to the previous set class if on the second layer and diagonally down to the left when it is on the fourth layer. If there is no set class to the left it will be mapped into a multiset when it is on the first layer, and diagonally down to the left when on the second, third, and fourth layers. Adding or subtracting one semitone to the second member displaces the set straight upward or downward respectively (vertical movement). The possible results when there are no set classes available in the next position can be verified in Figure 4. Adding or subtracting one semitone to the first member displaces the set diagonally upright or diagonally left-down respectively (diagonal movement). Note the peculiar results found on $\mathrm{sc}(048)$ where all results return to the previous set class disregarding the operation.

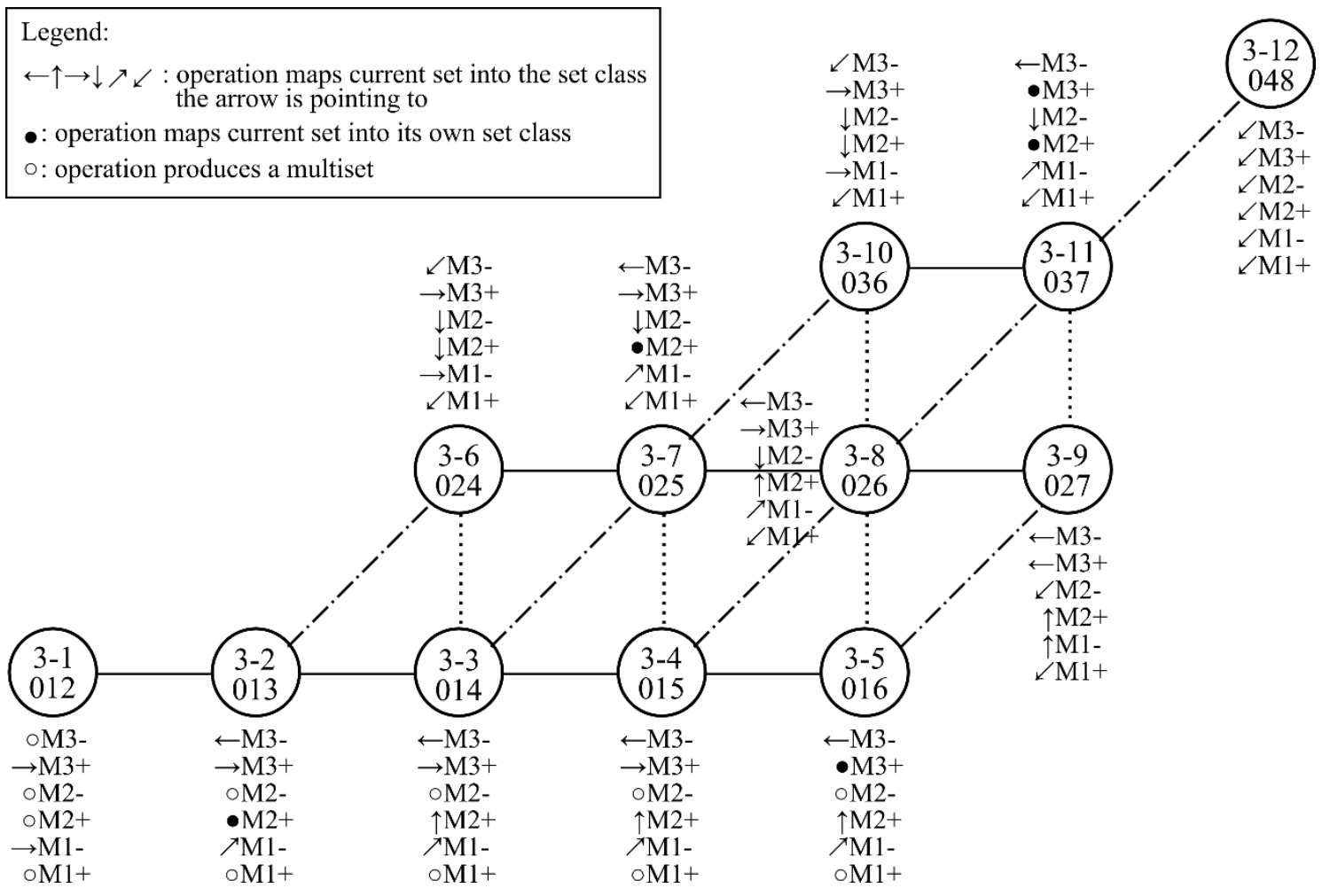

Figure 4: Atonal voice-leading space with original operations

Consider now what happen when extending the voice-leading space by applying the same kind of operations to two members simultaneously taken two by two as presented in Table 2 (same conventions are applied here) and its related 
BORDINI, Ricardo. 2018. Expanded Atonal Voice-Leading Space for Trichords: an auxiliary model for generating pre-compositional material. MUSICA THEORICA. Salvador: TeMA, 201805, p. 108-127.

Figure 5. Oddly enough, they produce the exact same map as in Figure 4 but with different mappings.

\begin{tabular}{|l|l|l|l|l|l|l|}
\hline & \multicolumn{1}{|c|}{ M1+|M2+ } & \multicolumn{1}{|c|}{ M1-|M2- } & \multicolumn{1}{|c|}{ M1+|M3+ } & \multicolumn{1}{|c|}{ M1-|M3- } & \multicolumn{1}{|c|}{ M2+|M3+ } & \multicolumn{1}{|c|}{ M2-|M3- } \\
\hline$(012)$ & $(122)$ & $(\mathrm{B} 02)=(013)$ & $(113)$ & (B11) & $(023)=(013)$ & $(001)$ \\
\hline$(013)$ & $(123)=(012)$ & $(\mathrm{B} 03)=(014)$ & $(114)$ & $(\mathrm{B} 12)=(013)$ & $(024)$ & $(002)$ \\
\hline$(014)$ & $(124)=(013)$ & $(\mathrm{B} 04)=(015)$ & $(115)$ & $(\mathrm{B} 13)=(024)$ & $(025)$ & $(003)$ \\
\hline$(015)$ & $(125)=(014)$ & $(\mathrm{B} 05)=(016)$ & $(116)$ & $(\mathrm{B} 14)=(025)$ & $(026)$ & $(004)$ \\
\hline$(016)$ & $(126)=(015)$ & $(\mathrm{B} 06)=(016)$ & $(117)$ & $(\mathrm{B} 15)=(026)$ & $(027)$ & $(005)$ \\
\hline$(024)$ & $(134)=(013)$ & $(\mathrm{B} 14)=(025)$ & $(125)=(014)$ & $(\mathrm{B} 23)=(014)$ & $(035)=(025)$ & $(013)$ \\
\hline$(025)$ & $(135)=(024)$ & $(\mathrm{B} 15)=(026)$ & $(126)=(015)$ & $(\mathrm{B} 24)=(025)$ & $(036)$ & $(014)$ \\
\hline$(026)$ & $(136)=(025)$ & $(\mathrm{B} 16)=(027)$ & $(127)=(016)$ & $(\mathrm{B} 25)=(036)$ & $(037)$ & $(015)$ \\
\hline$(027)$ & $(137)=(026)$ & $(\mathrm{B} 17)=(026)$ & $(128)=(016)$ & $(\mathrm{B} 26)=(037)$ & $(038)=(037)$ & $(016)$ \\
\hline$(036)$ & $(146)=(025)$ & $(\mathrm{B} 26)=(037)$ & $(137)=(026)$ & $(\mathrm{B} 35)=(026)$ & $(047)=(037)$ & $(025)$ \\
\hline$(037)$ & $(147)=(036)$ & $(\mathrm{B} 27)=(037)$ & $(138)=(027)$ & $(\mathrm{B} 36)=(037)$ & $(048)$ & $(026)$ \\
\hline$(048)$ & $(158)=(037)$ & $(\mathrm{B} 38)=(037)$ & $(149)=(037)$ & $(\mathrm{B} 47)=(037)$ & $(059)=(037)$ & $(037)$ \\
\hline
\end{tabular}

Table 2: Results applying the same operation to two members simultaneously

To this point, it seems it is of great interest to composers to know where they can move and also know how the movement can be done. Using different operations with obvious implications on the musical surface, a composer can attain noticeable variety yet maintain the overall unchanged sonority while smoothly transitioning through the space.

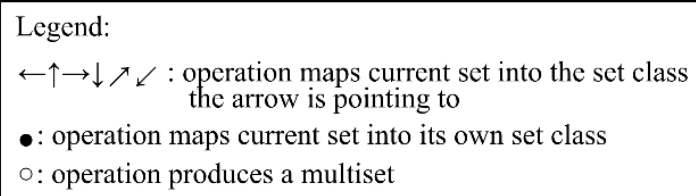

•: operation maps current set into its own set class

$\circ$ : operation produces a multiset

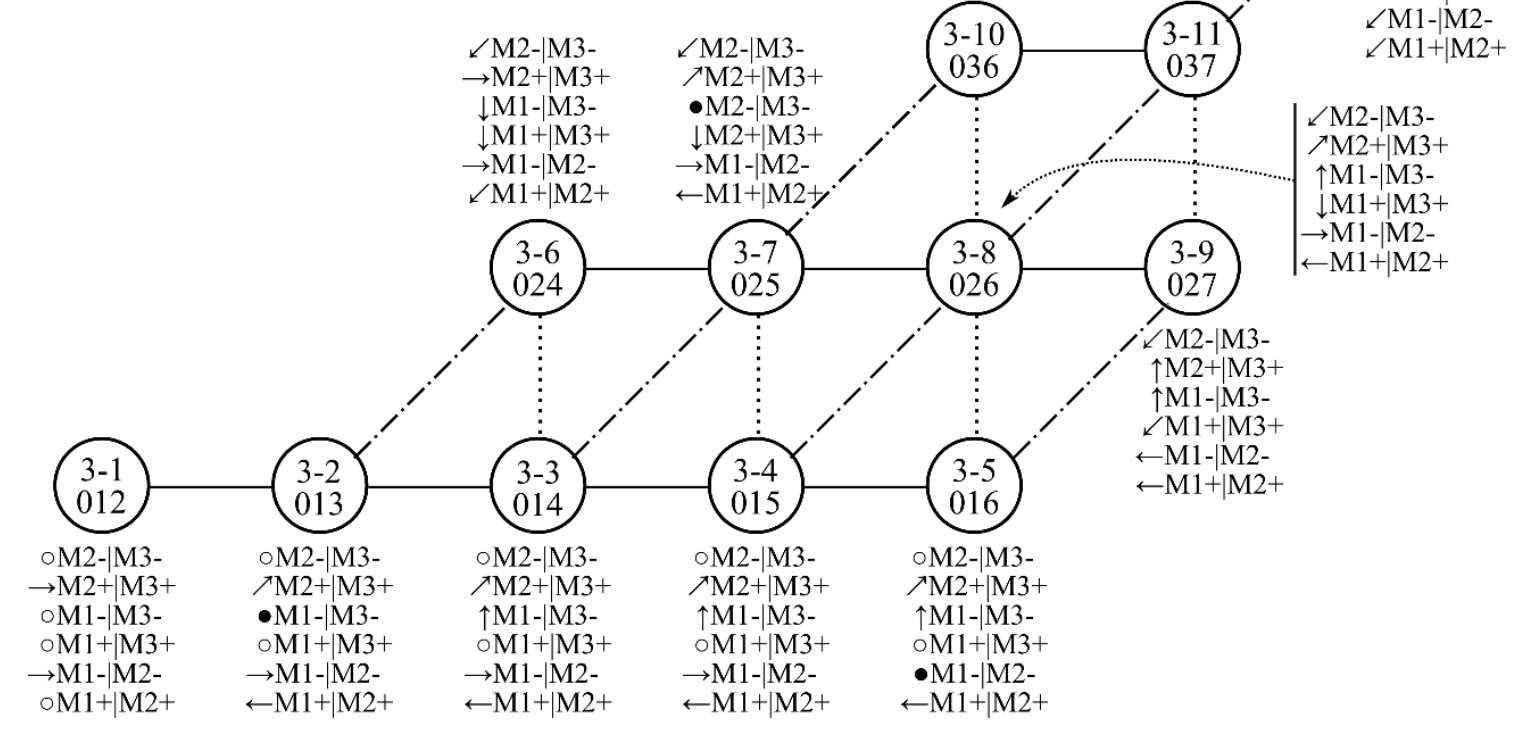

Figure 5: Atonal voice-leading space same operation applied to two members simultaneously 
BORDINI, Ricardo. 2018. Expanded Atonal Voice-Leading Space for Trichords: an auxiliary model for generating pre-compositional material. MUSICA THEORICA. Salvador: TeMA, 201805, p. 108-127.

A different situation arises when taking members two by two but applying different kinds of operations i.e., complementary operations of addition and subtraction. Set classes with bold faces in Table 3 represent the curved dashed lines in Example 6. Table 3 and Figure 6 exemplify these operations. Additional conventions used in Table 3 and 4: pale red shadowed cells refer to operations producing sum-classes greater than 2 or lesser than -2 .

\begin{tabular}{|c|c|c|c|c|c|c|}
\hline & M1+|M2- & M1-|M2+ & M1+|M3- & M1-|M3+ & M2+|M3- & M2-[M3+ \\
\hline (012) & $(102)=(012)$ & (B22) & (111) & $(B 13)=(024)$ & $(021)=(012)$ & $(003)$ \\
\hline (013) & $(103)=(013)$ & $(B 23)=(014)$ & (112) & $(B 14)=(025)$ & $(022)$ & $(004)$ \\
\hline$(014)$ & $(104)=(014)$ & $(B 24)=(025)$ & (113) & $(B 15)=(026)$ & $(023)=(013)$ & $(005)$ \\
\hline$(015)$ & $(105)=(015)$ & $(B 25)=(036)$ & (114) & $(B 16)=(027)$ & (024) & $(006)$ \\
\hline$(016)$ & $(106)=(016)$ & $(B 26)=(037)$ & (115) & $(B 17)=(026)$ & (025) & $(007)$ \\
\hline$(024)$ & (114) & $(B 34)=(015)$ & $(123)=(012)$ & $(B 25)=(036)$ & $(033)$ & (015) \\
\hline$(025)$ & (115) & $(B 35)=(026)$ & $(124)=(013)$ & $(B 26)=(037)$ & $(034)=(014)$ & (016) \\
\hline$(026)$ & $(116)$ & $(B 36)=(037)$ & $(125)=(014)$ & $(B 27)=(037)$ & $(035)=(025)$ & $(017)=(016)$ \\
\hline$(027)$ & $(117)$ & $(B 37)=(048)$ & $(126)=(015)$ & $(B 28)=(036)$ & $(036)$ & $(018)=(015)$ \\
\hline$(036)$ & $(126)=(015)$ & $(B 46)=(027)$ & $(135)=(024)$ & $(B 37)=(048)$ & $(045)=(015)$ & (027) \\
\hline$(037)$ & $(127)=(016)$ & $(B 47)=(037)$ & $(136)=(025)$ & $(B 38)=(037)$ & $(046)=(026)$ & $(028)=(026)$ \\
\hline$(048)$ & $(138)=(027)$ & $(\mathrm{B} 58)=(036)$ & $(147)=(036)$ & $(B 49)=(027)$ & $(057)=(027)$ & $(039)=(036)$ \\
\hline
\end{tabular}

Table 3: Results applying complementary operations to two members simultaneously

As can be seen in Figure 6 some operations produce original connections and some produce connections to set classes not connected by voice-leading semitone. What is more worth mentioning here is that this kind of operation produces those sets we have been pursuing: the missing diagonal represented by the curved dashed lines in Figures 3 and 6). 
BORDINI, Ricardo. 2018. Expanded Atonal Voice-Leading Space for Trichords: an auxiliary model for generating pre-compositional material. MUSICA THEORICA. Salvador: TeMA, 201805, p. 108-127.

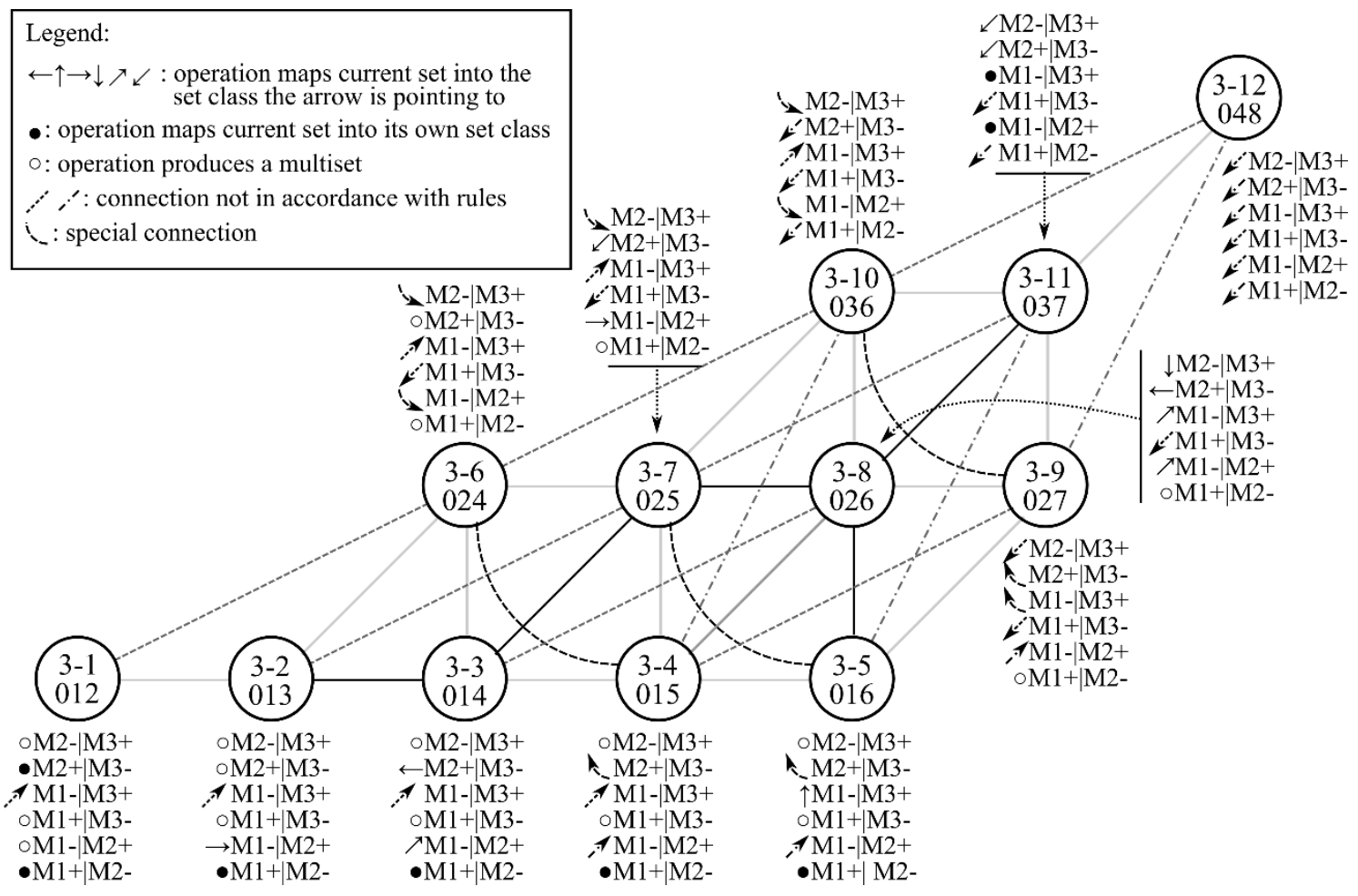

Figure 6: Atonal voice-leading space -

complementary operations applied to two members

The last possibility is to apply single operations to all three members at a time. In this case, applying the same kind of operation to three members just produces a transposition and so this procedure will not be considered here. However, applying the same kind of operation to two members while the complement is applied to the remaining member also produces some traditional connections and so they can be taken into consideration. Results are summarized on Table 4 and Figure 7.

\begin{tabular}{|l|l|l|l|l|l|l|}
\hline & $\mathrm{M} 1+|\mathrm{M} 2+| \mathrm{M} 3-$ & $\mathrm{M} 1-|\mathrm{M} 2-| \mathrm{M} 3+$ & $\mathrm{M} 1+|\mathrm{M} 2-| \mathrm{M} 3+$ & $\mathrm{M} 1-|\mathrm{M} 2+| \mathrm{M} 3-$ & $\mathrm{M} 1-|\mathrm{M} 2+| \mathrm{M} 3+$ & $\mathrm{M} 1+|\mathrm{M} 2-| \mathrm{M} 3-$ \\
\hline$(012)$ & $(121)$ & $(\mathrm{B} 03)=(014)$ & $(103)=(013)$ & $(\mathrm{B} 21)=(013)$ & $(\mathrm{B} 23)=(014)$ & $(101)$ \\
\hline$(013)$ & $(122)$ & $(\mathrm{B} 04)=(015)$ & $(104)=(014)$ & $(\mathrm{B} 22)$ & $(\mathrm{B} 24)=(025)$ & $(102)=(012)$ \\
\hline$(014)$ & $(123)=(012)$ & $(\mathrm{B} 05)=(016)$ & $(105)=(015)$ & $(\mathrm{B} 23)=(014)$ & $(\mathrm{B} 25)=(036)$ & $(103)=(013)$ \\
\hline$(015)$ & $(124)=(013)$ & $(\mathrm{B} 06)=(016)$ & $(106)=(016)$ & $(\mathrm{B} 24)=(025)$ & $(\mathrm{B} 26)=(037)$ & $(104)=(014)$ \\
\hline$(016)$ & $(125)=(014)$ & $(\mathrm{B} 07)=(015)$ & $(107)=(016)$ & $(\mathrm{B} 25)=(036)$ & $(\mathrm{B} 27)=(037)$ & $(105)=(015)$ \\
\hline$(024)$ & $(133)$ & $(\mathrm{B} 15)=(026)$ & $(115)$ & $(\mathrm{B} 33)$ & $(\mathrm{B} 35)=(026)$ & $(113)$ \\
\hline$(025)$ & $(134)=(013)$ & $(\mathrm{B} 16)=(027)$ & $(116)$ & $(\mathrm{B} 34)=(015)$ & $(\mathrm{B} 36)=(037)$ & $(114)$ \\
\hline$(026)$ & $(135)=(024)$ & $(\mathrm{B} 17)=(026)$ & $(117)$ & $(\mathrm{B} 35)=(026)$ & $(\mathrm{B} 37)=(048)$ & $(115)$ \\
\hline$(027)$ & $(136)=(025)$ & $(\mathrm{B} 18)=(025)$ & $(118)$ & $(\mathrm{B} 36)=(037)$ & $(\mathrm{B} 38)=(037)$ & $(116)$ \\
\hline$(036)$ & $(145)=(014)$ & $(\mathrm{B} 27)=(037)$ & $(127)=(016)$ & $(\mathrm{B} 45)=(016)$ & $(\mathrm{B} 47)=(037)$ & $(125)=(014)$ \\
\hline$(037)$ & $(146)=(025)$ & $(\mathrm{B} 28)=(036)$ & $(128)=(016)$ & $(\mathrm{B} 46)=(027)$ & $(\mathrm{B} 48)=(037)$ & $(126)=(015)$ \\
\hline$(048)$ & $(157)=(026)$ & $(\mathrm{B} 39)=(026)$ & $(139)=(026)$ & $(\mathrm{B} 57)=(026)$ & $(\mathrm{B} 59)=(026)$ & $(137)=(026)$ \\
\hline
\end{tabular}

Table 4: Results of operations applied to three members 
BORDINI, Ricardo. 2018. Expanded Atonal Voice-Leading Space for Trichords: an auxiliary model for generating pre-compositional material. MUSICA THEORICA. Salvador: TeMA, 201805, p. 108-127.

There are few admissible original connections in Figure 7 but still interesting to note are the connections that "skip over" adjoined set classes, which can be used compositionally in many interesting ways.

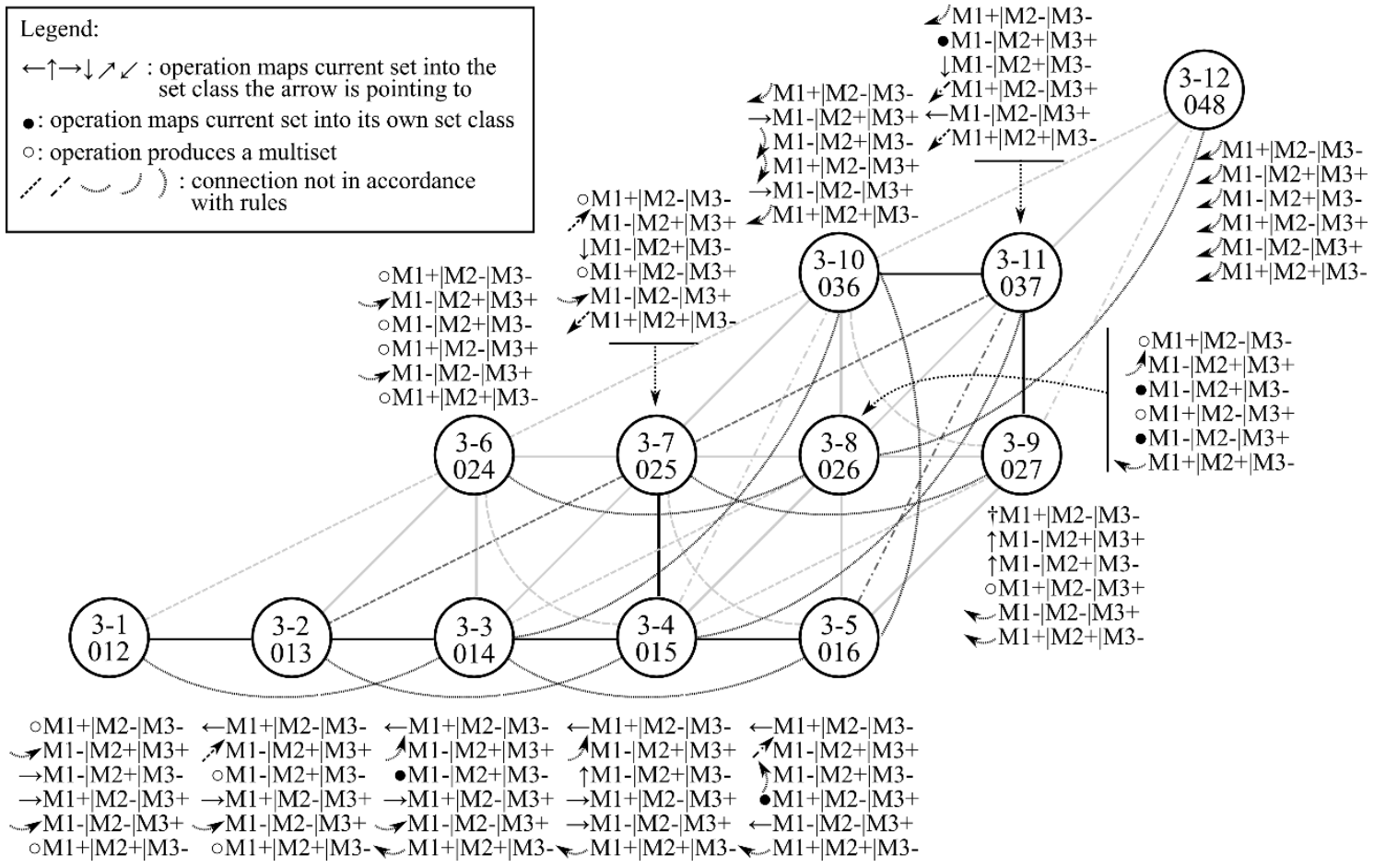

Figure 7: Results of operations applied to three members

Table 5 below presents a complete tabulation of all available ways to move from set class to set class in the voice-leading space. Admitted operations are the original ones plus all others just discussed as long as they fulfill the rules for sumclasses. It supplements Figure 3 further above which is now consolidated as the proposed expanded voice-leading space.

A last comment on Tables 1, 2, 3, and 4 addresses set classes having inversional symmetry. Compare the rows for set classes 3-1(012), 3-6(024), 39(027), 3-10(036), and 3-12(048). They all contain symmetrical results as long as multisets and operations not admitted are disregarded. For example, the results of operations applied to sc(024) in Table 2 are: (013), (025), (014), (014), (025), and (013). The last three mirror the first three. 
BORDINI, Ricardo. 2018. Expanded Atonal Voice-Leading Space for Trichords: an auxiliary model for generating pre-compositional material. MUSICA THEORICA. Salvador: TeMA, 201805, p. 108-127.

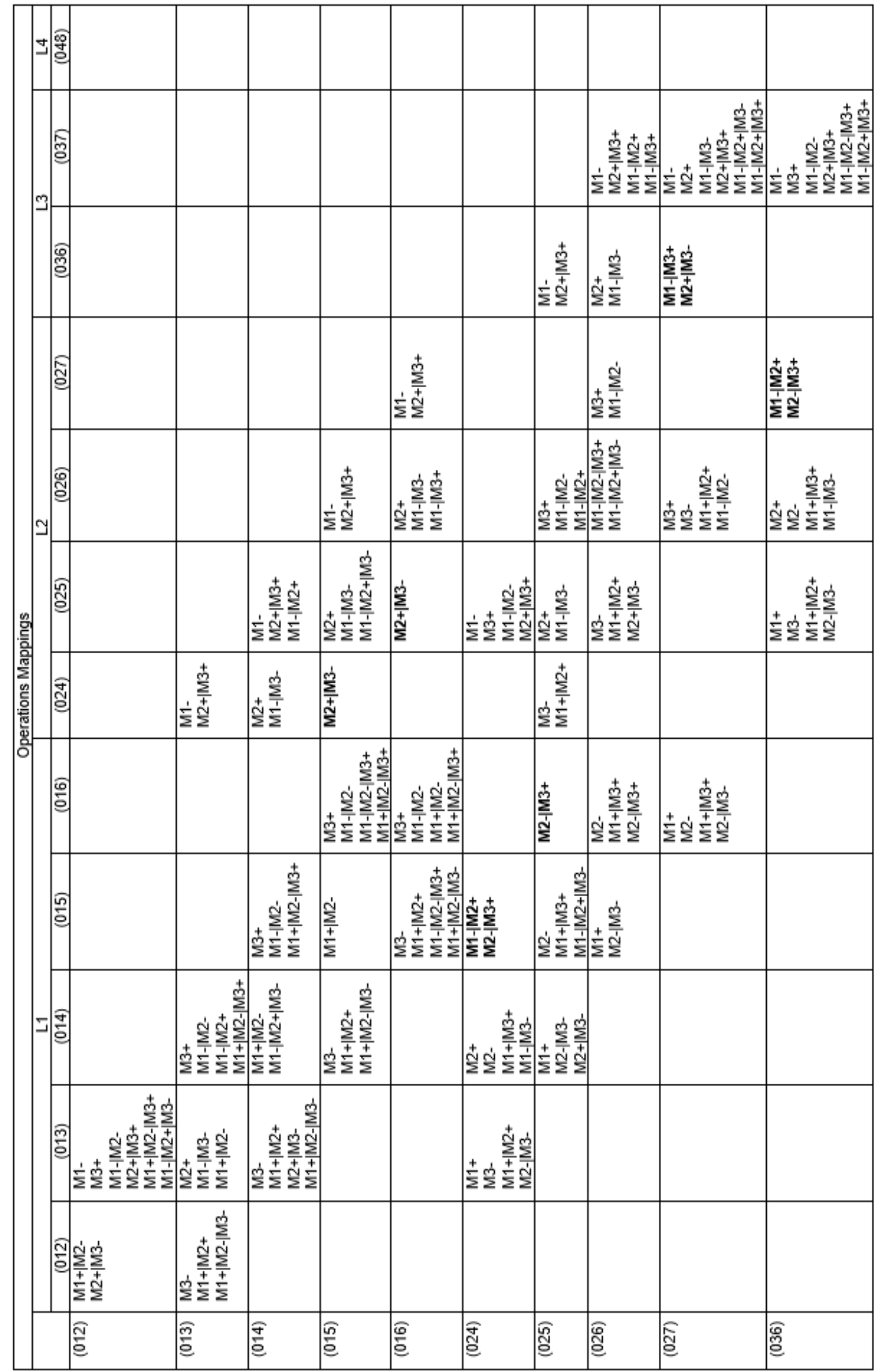


BORDINI, Ricardo. 2018. Expanded Atonal Voice-Leading Space for Trichords: an auxiliary model for generating pre-compositional material. MUSICA THEORICA. Salvador: TeMA, 201805, p. 108-127.

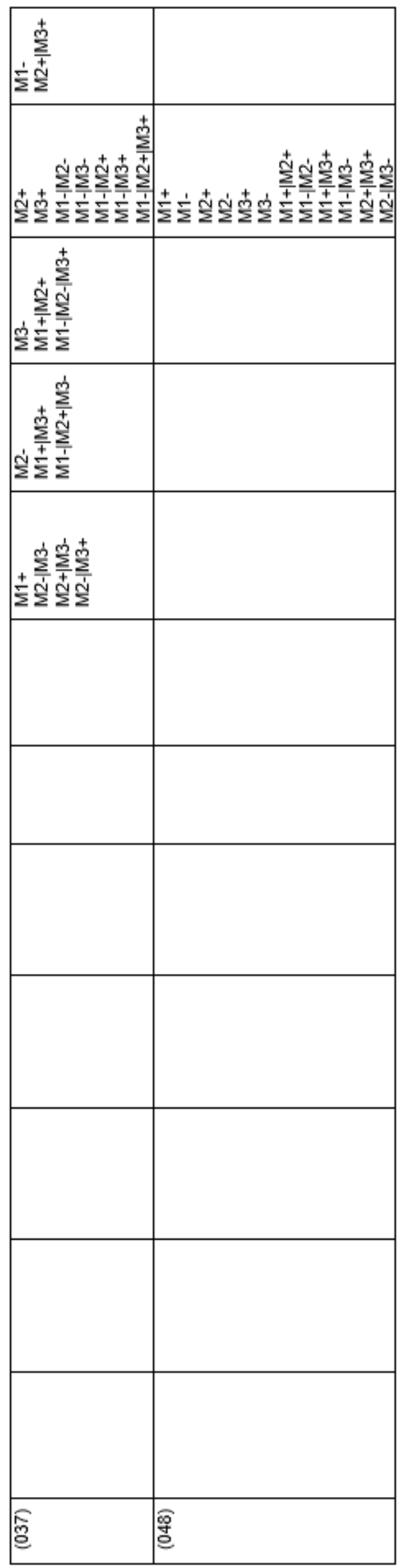

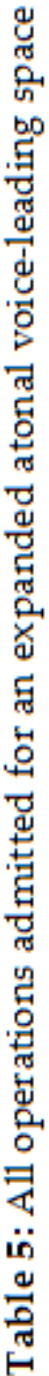

\section{MUSICA THEORICA}

Revista da Associação Brasileira de Teoria e Análise Musical Journal of the Brazilian Society for Music Theory and Analysis @ TeMA 2018 - ISSN 2525-5541 
BORDINI, Ricardo. 2018. Expanded Atonal Voice-Leading Space for Trichords: an auxiliary model for generating pre-compositional material. MUSICA THEORICA. Salvador: TeMA, 201805, p. 108-127.

\section{Pathways}

As previously stated, different qualities of movement within the voiceleading space allied with the proved diversity of operations capable of mapping and chaining set classes within the voice-leading space yield the concept of traversing it partially or entirely through a series of pathways.

Atonal voice-leading pathways can be of great help to composers trying to define a "coherent" path. Indeed, one is not supposed to use all set classes in only one movement or even in an entire piece, but it can be done and with interesting results. One cannot traverse voice-leading pathways from the very first to the very last set classes without repeating at least one set class unless one uses at least one curved dashed path.

Of the many different paths to cross the space, three can be considered the shortest and smoothest. Figure 8 shows two pathways fairly straight and a third one which keeps alternating layers that is not as smooth. This is still interesting due to the higher degree of different quality connector. Both examples in Figures $8 \mathrm{a}$ and $8 \mathrm{~b}$ use all three dashed connectors but in a different order and have the same succession of sum numbers. "Shortcuts" used in Figure 4 are handy to notate and keep track of a path through the voice-leading space during the precompositional process.

a)

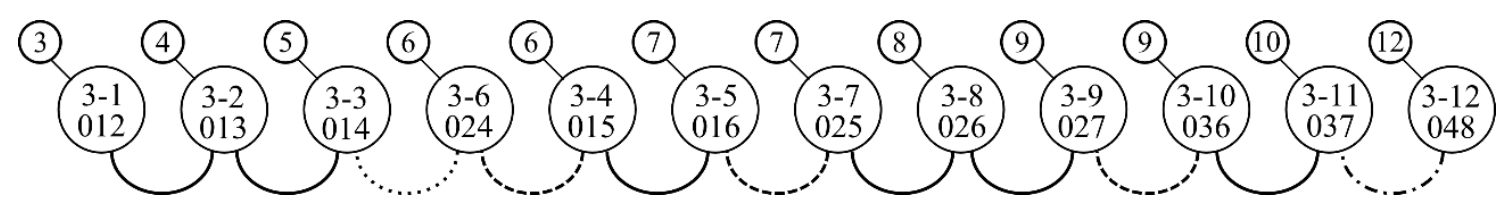

b)

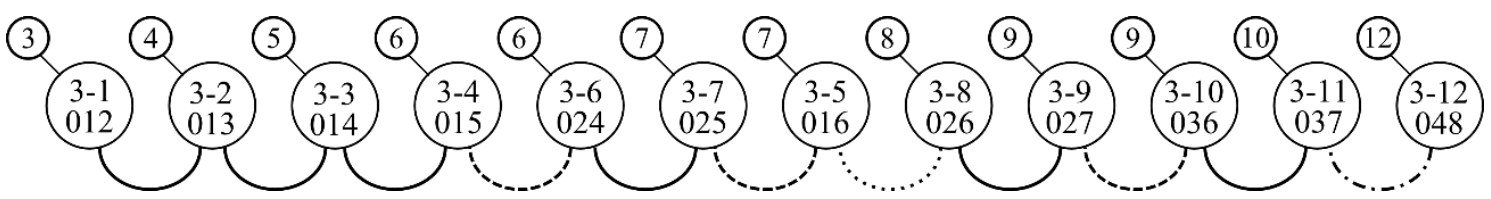

c)

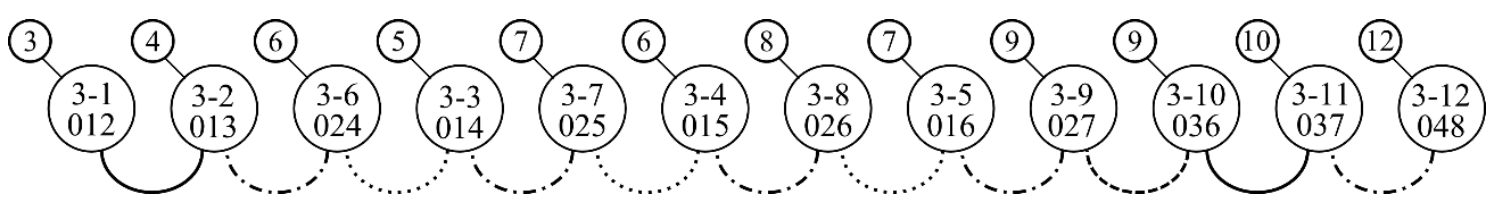

Figure $8(a, b, c)$ : Shortest and smoothest complete traverse pathways

Comparing Figures $8 \mathrm{a}$ and $8 \mathrm{~b}$, one can observe that smoothness is obtained through extensive use of the six solid line connectors, three dashed ones, one dotted connector and one dash-dotted connector. The pathway in 
BORDINI, Ricardo. 2018. Expanded Atonal Voice-Leading Space for Trichords: an auxiliary model for generating pre-compositional material. MUSICA THEORICA. Salvador: TeMA, 201805, p. 108-127.

Figure $8 \mathrm{c}$ is also short, but not as smooth. One can see that the sum numbers offer a more dynamic interchange of different connectors: five dash-dotted, three dotted, two solid, and just one dashed. Observe the interval expansion and contraction it supplies.

Among the great variety of pathways to traverse the voice-leading space, one can notice the two greatest one-kind connector paths. The bottom layer uses only solid line connectors and comprises five set classes ranging from sc(012) through sc(016). The largest diagonal path comprising of four set classes uses only dash-dotted connectors ranging from sc(015) through sc(048). This last one features a unique path progression since both their last two members keep increasing their intervals uniformly throughout the path (see Figure 3). An additional interesting configuration is obtained using the second layer set classes connected only by solid lines and that same diagonal connected only by dashdotted lines. One can use $\mathrm{sc}(026)$ as a common axis creating a symmetrical ordering.

Another remarkable feature is the centric role sc(026) plays within the voice-leading space. It is the only set class that connects reciprocally with two different set classes in two adjacent layers, besides two set classes in its same layer. It has connections with six different set classes two by two in three different layers. Also sc(025) has six different connections except that it has a different number of sets in each layer. It has three connections with the layer below, two with sets in its own layer and one with the layer above it. In the quick reference guide items $6 \mathrm{~g}$ and $6 \mathrm{~h}$ at the end of this paper these two sets and their connections are shown. Notice the differences regarding connector types and path's symmetry.

There are many different possible pathways to navigate the space. Taking $\mathrm{sc}(026)$ and sc(025) as centric sets in Figure 9 show of some of more obvious ones. Figure 9a depicts a path starting on sc(026) at the center of its sub-space and going up to $\mathrm{sc}(036)$ or left to $\mathrm{sc}(025)$ and then moving clockwise or counter-clockwise until returning to the starting point. An optional path indicated by a light grey double point arrow shows a skip when completing the circular movement without returning to the center. After completing the circle it provides an interesting point from which to transpose or invert used set classes and restart again. Figure $9 \mathrm{~b}$ shows a variation that yet maintaining $\mathrm{sc}(026)$ at the center alternates it with other set classes inside its space. Starting at the center one can move up to $\mathrm{sc}(036)$, move right to $\mathrm{sc}(037)$ and return to the center and restart the pattern cyclically with the other sets. There are many different starting points in clockwise or counter-clockwise movement. 

model for generating pre-compositional material. MUSICA THEORICA. Salvador: TeMA, 201805, p. 108-127.
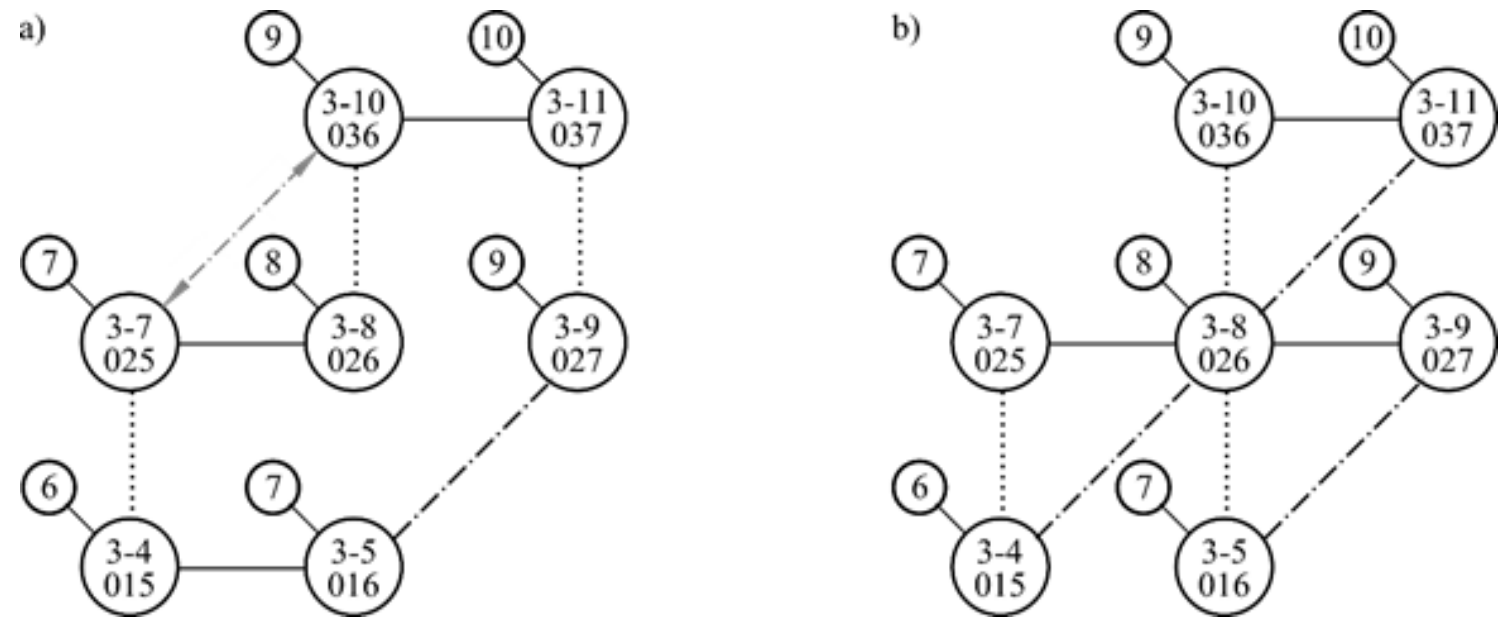

Figure $9(\mathbf{a}, \mathbf{b})$ : Set classes with centric roles and some possible pathways

Figures $9 \mathrm{c}$ and $9 \mathrm{~d}$ show the same above procedures except that they are related to $\mathrm{sc}(025)$. All of what has been said about $\mathrm{sc}(026)$ can be applied to $\mathrm{sc}(025)$. Considering the quality of connectors and shape of patterns, compare the differences regarding Figures $9 \mathrm{~b}$ and $9 \mathrm{~d}$. For example, an interesting structure could proceed as in Figure $9 \mathrm{~b}$ and the other as in Figure 9d.

c)

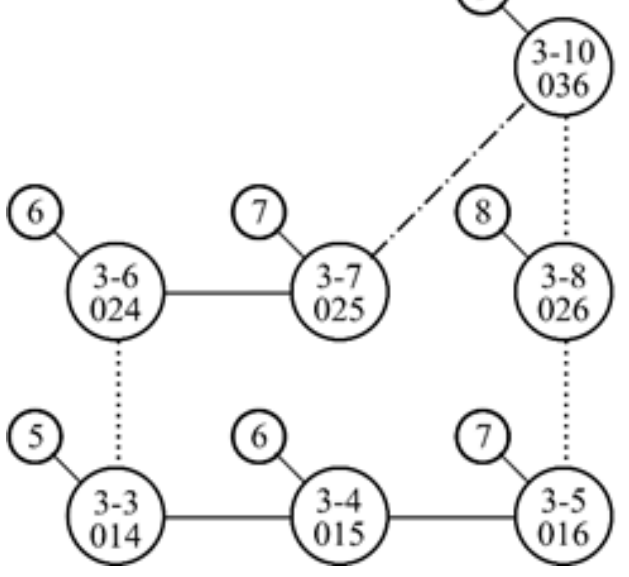

d)

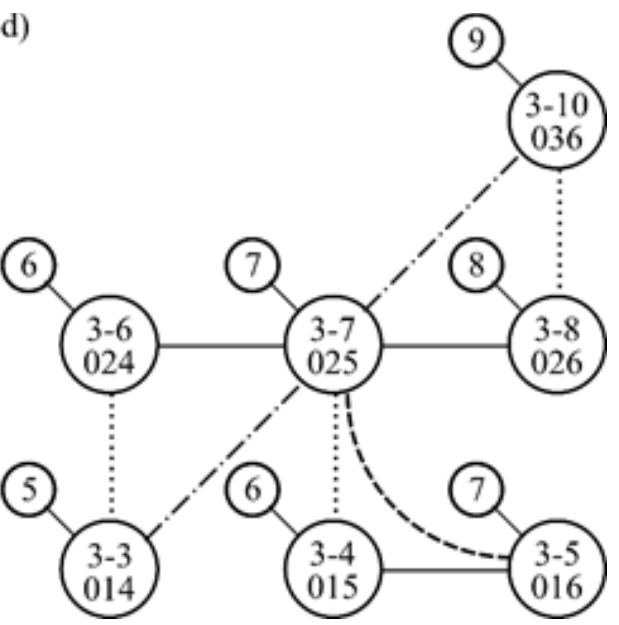

Figure 9 (c, d): Set classes with centric roles and some possible pathways

Still another possible pathway includes one voice circling through the outside circle with another voice fixed in the center or without a center as in Figure 9e. Consider also the differences concerning Figures 9e and $9 \mathrm{f}$. 
BORDINI, Ricardo. 2018. Expanded Atonal Voice-Leading Space for Trichords: an auxiliary model for generating pre-compositional material. MUSICA THEORICA. Salvador: TeMA, 201805, p. 108-127.

e)

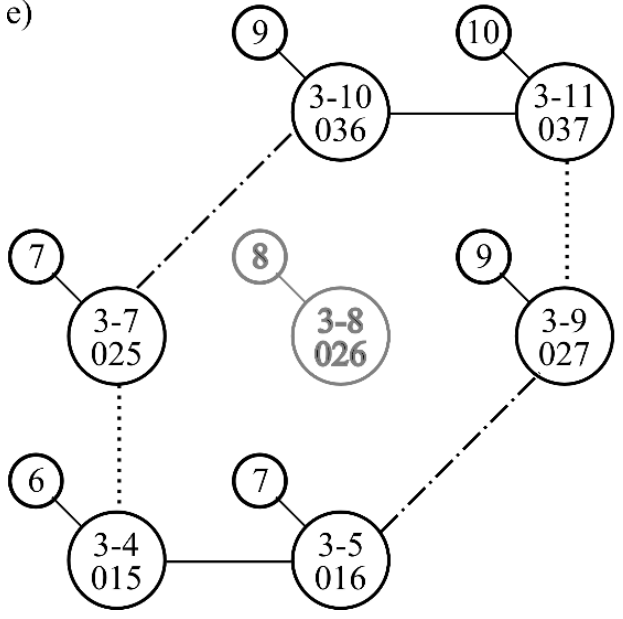

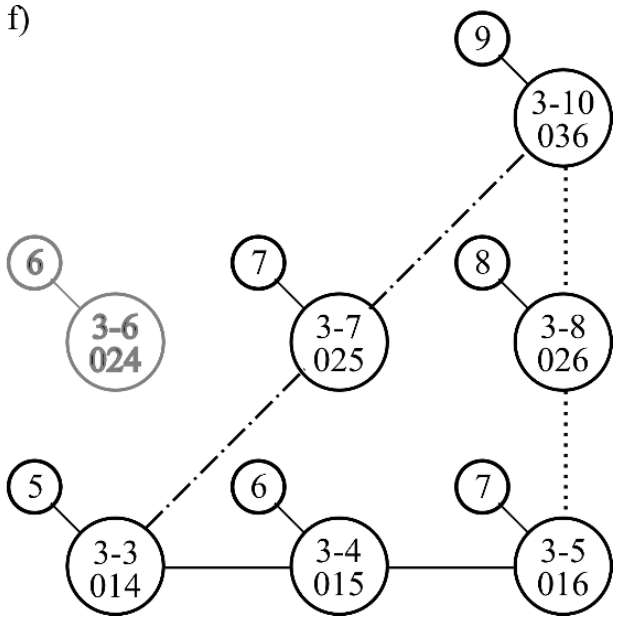

Figure $9(\mathbf{e}, \mathbf{f})$ : Set classes with centric roles and some possible pathways

Finally, from the many choices available a composer can create a variety of pathways for trichords that are obtained by moving toward set classes that are not immediately connected in the space. Some will be smoother than others, both with good results depending on one's individual compositional craftsmanship.

\section{Quick Reference Guide}

The last part of this paper is a quick reference guide for voice-leading subspaces for trichords. Starting with any set class, all its surrounding connections are shown so one can assess their connection qualities and their layer relationship, selecting those that are more suitable to one's purpose. Some pathways will function like inversions or transpositions in relation to one another. It is up to the composer's discretion to use adjacent paths or angular paths to more distant related set classes. 
BORDINI, Ricardo. 2018. Expanded Atonal Voice-Leading Space for Trichords: an auxiliary model for generating pre-compositional material. MUSICA THEORICA. Salvador: TeMA, 201805, p. 108-127.

\section{Quick reference guide for atonal voice-leading sub-spaces for trichords}

(3)
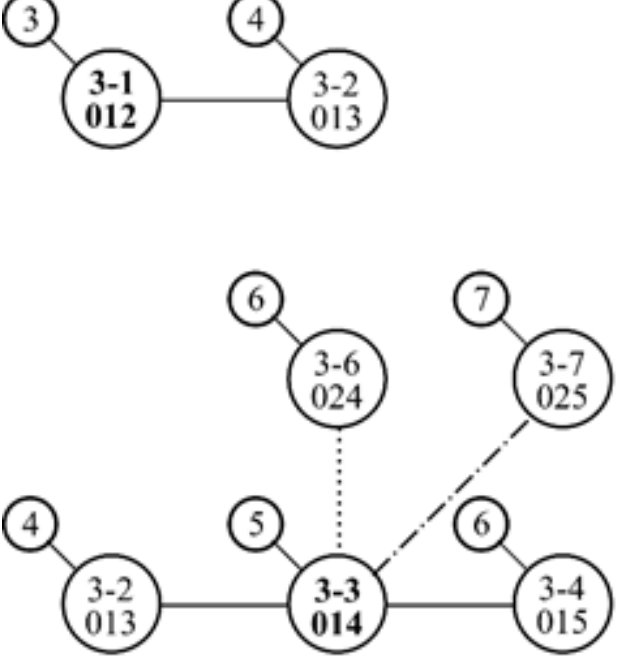

(7)

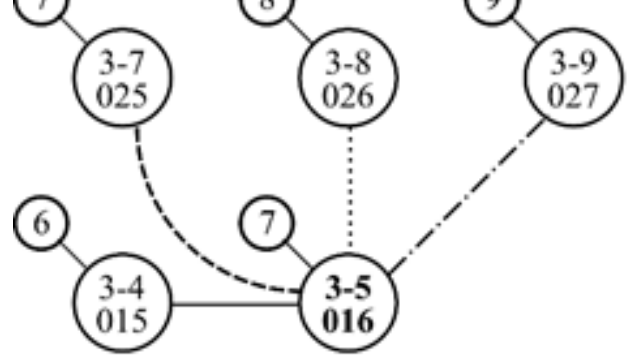

(9)

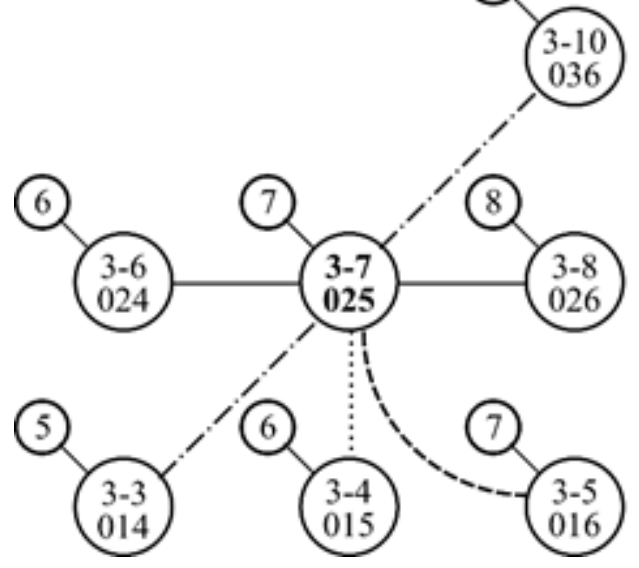

(6)

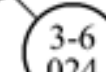

024.
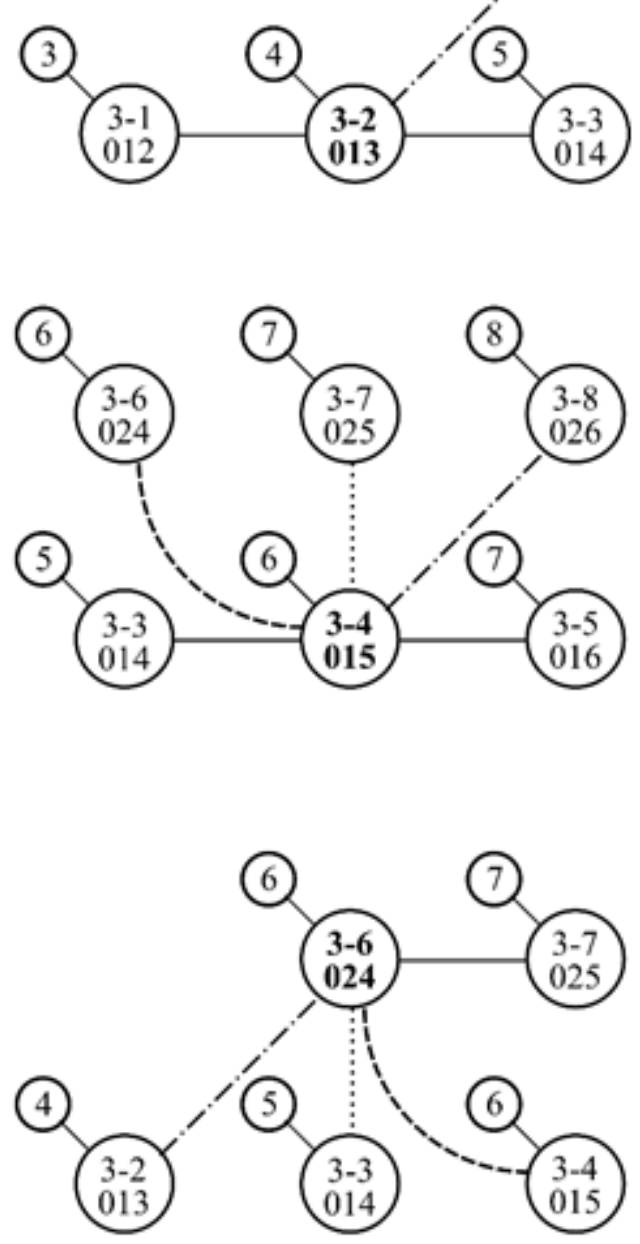

(9)

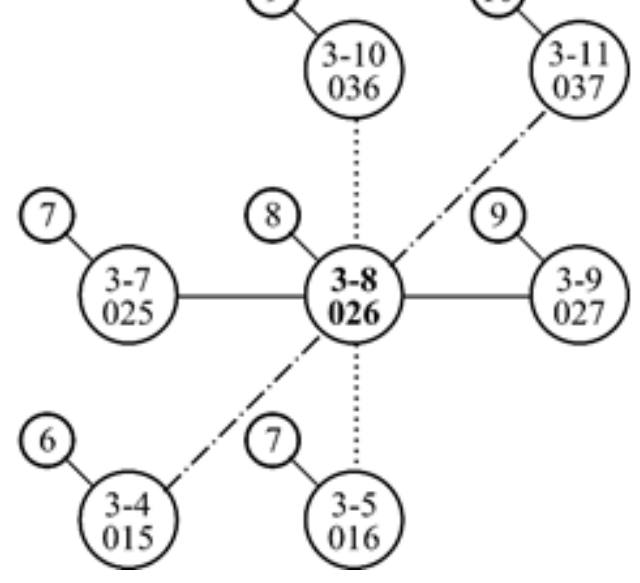


BORDINI, Ricardo. 2018. Expanded Atonal Voice-Leading Space for Trichords: an auxiliary model for generating pre-compositional material. MUSICA THEORICA. Salvador: TeMA, 201805, p. 108-127.
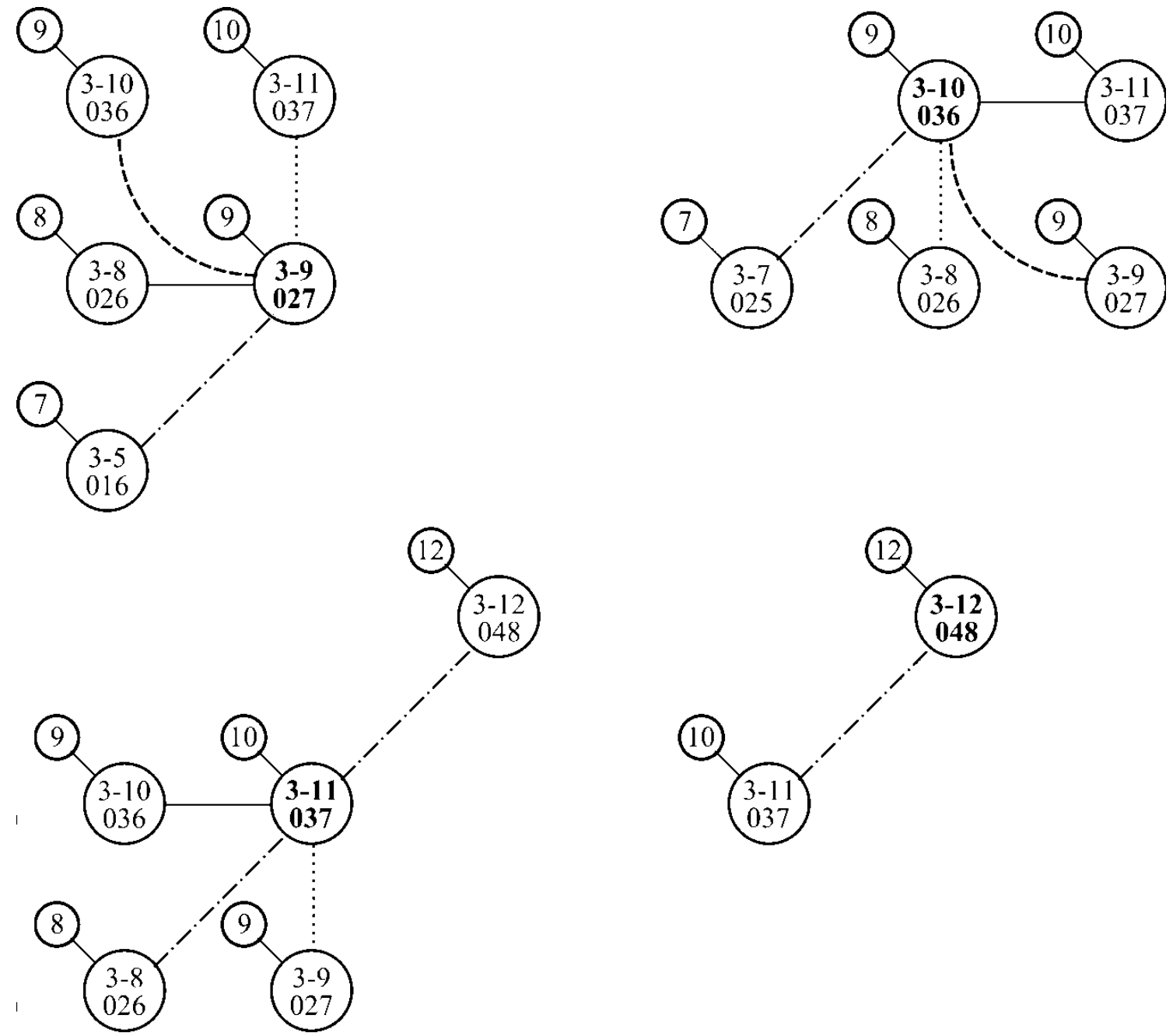

\section{References}

1. Callender, Clifton, Ian Quinn, and Dmitri Tymoczko. 2008. Generalized VoiceLeading Spaces. Science 320, p. 346-348.

2. Cohn, Richard. 1998. Square Dances with Cubes. Journal of Music Theory 42, no 2, p. 283-296.

3. 2003. A Tetrahedral Graph of Tetrachordal Voice-Leading Space. Music Theory Online 9, no 4, p. 1-19.

4. Cook, Robert C. 2005. Parsimony and Extravagance. Journal of Music Theory 49, no 1, p. 109-140.

5. Morris, Robert. 1998. Voice-Leading Spaces. Music Theory Spectrum 20, no 2, p.175-208.

6. Straus, Joseph N. 2005. Introduction to Post-Tonal Theory. $3^{\text {rd }}$ ed. New York: Pearson.

7. Tymoczko, Dmitri. 2011. A Geometry of Music: Harmony and Counterpoint in the Extended Common Practice. Oxford: Oxford University Press. 